\title{
Combination versus single-agent as palliative chemotherapy for gastric cancer
}

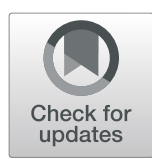

Jin-Hyuk Choi ${ }^{1+}$, Yong Won Choi ${ }^{1 \dagger}$, Seok Yun Kang ${ }^{1 \dagger}$, Geum Sook Jeong ${ }^{1}$, Hyun Woo Lee ${ }^{1}$, Seong Hyun Jeong ${ }^{1}$, Joon Seong Park', Mi Sun Ahn ${ }^{1 *}$ (D) and Seung Soo Sheen ${ }^{2}$

\begin{abstract}
Background: Although combination chemotherapy (CC) is generally recommended in recurrent or primary metastatic gastric cancer (RPMGC), the results of randomized trials are conflicting.

Methods: A retrospective review was conducted on 687 RPMGC patients who received palliative chemotherapy. We compared the overall survival (OS) between CC and single-agent chemotherapy (SC) among these patients, and we analyzed the clinicopathological characteristics affecting outcome including neutrophil-to-lymphocyte ratio (NLR) and platelet-to-lymphocyte ratio (PLR).

Results: Although 521 patients (75.8\%) underwent CC, SC was more frequently performed in elderly patients (57.6\%) and ECOG performance status (PS) 2 or $3(65.8 \%)$ patients ( $p<0.0001$, in each case). The median OS of patients who received CC was significantly longer than that of patients who received SC (11 vs. 8 months, $p<0.0001$ ). No difference in OS between CC and SC was observed in elderly patients $(p=0.583)$, poor PS $(p=0.810)$, signet ring cell $(p=0.347)$, palliative surgical resection ( $p=0.307)$, and high PLR $(p=0.120)$, with a significant interaction between age and type of regimen ( $p=0.012)$. Moreover, there was no difference in OS between CC and SC after propensity score matching $(p=0.322)$. Multivariate analysis revealed that palliative resection and $\geq$ second-line chemotherapy were independently associated with favorable OS ( $p<0.0001$, in each case), whereas poor PS ( $p=0.004)$, signet ring cell $(p<0.0001)$, peritoneal metastasis $(p=0.04)$, high NLR $(p=0.001)$, and high PLR $(p=0.033)$ were independent prognostic factors of poor OS.
\end{abstract}

Conclusions: Although CC is the standard of care in RPMGC, SC can be considered a reasonable option in certain subgroups, such as elderly patients.

Keywords: Gastric cancer, Palliative chemotherapy, Single, Combination, Platelet-to-lymphocyte ratio, Age

\section{Background}

Gastric cancer (GC) is the most common malignancy in Korea and the second leading cause of cancer-related death worldwide $[1,2]$. For patients with recurrent or primary metastatic GC (RPMGC), palliative chemotherapy is the standard of care. In terms of chemotherapy regimen,

\footnotetext{
* Correspondence: maruhiran@hanmail.net

${ }^{\dagger}$ Jin-Hyuk Choi, Yong Won Choi, and Seok Yun Kang contributed equally as first authors.

'Department of Hematology-Oncology, Ajou University School of Medicine, 164 World Cup-ro, Suwon, Yeongtong-gu 16499, South Korea

Full list of author information is available at the end of the article
}

combination chemotherapy $(\mathrm{CC})$ is generally recommended in clinical practice [3-7]. Two meta-analyses demonstrated a small but statistically significant survival benefit of CC compared to single-agent chemotherapy (SC) [6, 7]. However, individual randomized trials comparing $\mathrm{CC}$ and SC gave conflicting results $[4,6-10]$. Moreover, most randomized trials excluded patients who were elderly or who had poor performance status (PS) [3-5, 811]. Therefore, it is an important clinical issue to determine clearly whether $\mathrm{CC}$ is more beneficial than SC and

(c) The Author(s). 2020 Open Access This article is licensed under a Creative Commons Attribution 4.0 International License, which permits use, sharing, adaptation, distribution and reproduction in any medium or format, as long as you give appropriate credit to the original author(s) and the source, provide a link to the Creative Commons licence, and indicate if changes were made. The images or other third party material in this article are included in the article's Creative Commons licence, unless indicated otherwise in a credit line to the material. If material is not included in the article's Creative Commons licence and your intended use is not permitted by statutory regulation or exceeds the permitted use, you will need to obtain permission directly from the copyright holder. To view a copy of this licence, visit http://creativecommons.org/licenses/by/4.0/ The Creative Commons Public Domain Dedication waiver (http://creativecommons.org/publicdomain/zero/1.0/) applies to the data made available in this article, unless otherwise stated in a credit line to the data. 
to identify patient subgroups who may benefit from $\mathrm{SC}$ rather than CC.

There is increasing evidence that inflammation plays a critical role in the development and progression of cancers [12-14]. Many inflammation-based prognostic markers have been suggested as potential prognostic factors in various types of cancers [12-14]. Recently, as convenient and cost-effective blood-derived markers, the neutrophilto-lymphocyte ratio (NLR) and the platelet-to-lymphocyte ratio (PLR), which may reflect the inflammatory response, immune response, and coagulation status, have been widely investigated as useful prognostic factors in many solid tumors including GC [12-16].

In this study, we compared the overall survival (OS) between CC and SC in RPMGC patients, while analyzing the clinicopathological characteristics affecting outcome including NLR and PLR.

\section{Methods}

\section{Study population}

All histologically documented RPMGC patients who had started first-line palliative chemotherapy at Ajou University Hospital between January 2004 and December 2014 were retrospectively identified. Histologically documented case of RPMGC were eligible. In patients with primary metastatic disease, American Joint Committee on Cancer stage IV patients [17] with distant metastasis were included. Definition of primary metastatic disease in patients with surgical resection before chemotherapy was previously described [18]. Patients who had started first-line chemotherapy at other hospitals during this period and received further therapy at our institution were excluded.

All procedures performed in the study involving human participants were carried out in accordance with the ethical standards of the institutional and/or national research committee and with the 1964 Helsinki Declaration and its later amendments or comparable ethical standards. The protocol was reviewed and approved by the Institutional Review Board (IRB) of Ajou University Hospital (IRB approval no. AJIRB-MED-MDB-18-317). The IRB decided to waive the informed consent for this study because it was a retrospective study using anonymized data. Studies about third or further line of chemotherapy and palliative surgical resection, which included the majority of the patients of the present study cohort, were previously reported [18, 19]. However, the eligibility criteria of the current study were somewhat different from those of the previous ones with longer follow-up of patients $[18,19]$.

\section{Clinical review}

We retrospectively reviewed the medical records of the eligible patients. Data collected on the RPMGC patients included various clinicopathological characteristics of patients and survival information. Pathologic information on the primary tumor of the stomach in both primary metastatic and recurrent disease was used for histologic subclassification, while histology was classified according to the pathology report on the recurrent stomach lesion, if available, in local recurrence cases.

Complete blood count $(\mathrm{CBC})$ with differential count obtained just before first line chemotherapy was used to determine NLR and PLR. The NLR and PLR were calculated from the differential count by dividing the neutrophil or platelet count by the lymphocyte count. NLR or PLR greater than median values were defined a prior as high level.

\section{Statistical analysis}

OS was calculated using the Kaplan-Meier method. OS was defined as the time from the start day of first-line chemotherapy to death. Data on the survivors were censored at the last follow-up. The log-rank test was used for analysis of the differences between the survival curves. The comparison of the categorical variables between groups was performed by Fisher's exact test. The Cox proportional hazards regression model was applied to determine the joint effects of several variables on survival and to assess interactions between treatment and subgroups in subgroup analyses. In the Cox proportional hazards regression model, factors with $p$ values $<0.1$ in univariate analysis were included. All statistical analyses were performed two-sided using SPSS version 23.0 for Windows.

Propensity score matching (PSM) was applied to reduce selection bias by balancing covariates that may be associated with the outcome. In the current study, the 1: 1 nearest neighbor matching was performed using SPSS version 23.0 for Windows.

\section{Results}

\section{Patient characteristics}

Of the 692 patients who started first-line palliative chemotherapy at our institution for RPMGC, five patients without $\mathrm{CBC}$ data before first-line chemotherapy were excluded, leaving 687 patients for analysis.

Table 1 summarizes the patients' clinicopathological characteristics. Of the 687 patients, 478 (69.6\%) were male, 125 (18.2\%) were 70 years or older, with a median age of 57 (19-86), 611 (88.9\%) were in ECOG PS 0 or 1, and $186(27.1 \%)$ had poorly differentiated adenocarcinoma as the most prevalent histological type. A total of $314(45.7 \%)$ and $152(22.1 \%)$ patients had peritoneal and liver metastasis, respectively, and $32(4.7 \%)$ patients had both liver and peritoneal metastases. Of the 304 patients with recurrent disease, 274 had received adjuvant chemotherapy. Palliative surgical resection (gastrectomy: 82; metastasectomy: 42; both: 14) before first-line 
Table 1 Patients characteristics at the initiation of first-line chemotherapy

\begin{tabular}{|c|c|c|c|c|c|c|c|c|}
\hline \multirow[t]{3}{*}{ Characteristics } & \multicolumn{3}{|c|}{ Before propensity score matching } & \multirow[t]{3}{*}{$P$ value } & \multicolumn{3}{|c|}{ After propensity score matching } & \multirow{3}{*}{$\begin{array}{l}P \\
\text { value }\end{array}$} \\
\hline & \multirow{2}{*}{$\begin{array}{l}\text { Total N } \\
(\%)\end{array}$} & \multicolumn{2}{|c|}{ Chemotherapy } & & \multirow{2}{*}{$\begin{array}{l}\text { Total N } \\
(\%)\end{array}$} & \multicolumn{2}{|c|}{ Chemotherapy } & \\
\hline & & Single-agent & Combination & & & Single-agent & Combination & \\
\hline Gender & & & & 0.101 & & & & 0.672 \\
\hline Male & $478(69.6)$ & 107(64.5) & $371(71.2)$ & & $164(69.5)$ & $80(67.8)$ & $84(71.2)$ & \\
\hline Female & $209(30.4)$ & $59(35.5)$ & $150(28.8)$ & & $72(30.5)$ & $38(32.2)$ & $34(28.8)$ & \\
\hline Age (years) & & & & $<0.0001$ & & & & 0.88 \\
\hline$<70$ & $562(81.8)$ & $94(56.6)$ & $468(89.8)$ & & $160(67.8)$ & $79(66.9)$ & $81(68.6)$ & 9 \\
\hline$\geq 70$ & $125(18.2)$ & $72(43.4)$ & $53(10.2)$ & & $76(32.2)$ & $39(33.1)$ & $37(31.4)$ & \\
\hline PS (ECOG) & & & & $<0.0001$ & & & & 0.865 \\
\hline 0,1 & $611(88.9)$ & $116(69.9)$ & $495(95.0)$ & & $194(82.2)$ & $98(83.1)$ & $96(81.4)$ & \\
\hline 2,3 & $76(11.1)^{\mathrm{a}}$ & $50(30.1)$ & $26(5.0)$ & & $42(17.8)^{a}$ & $20(16.9)$ & $22(18.6)$ & \\
\hline Disease status & & & & 0.325 & & & & 0.696 \\
\hline Primary metastatic & $383(55.7)$ & $87(52.4)$ & $296(56.8)$ & & $116(49.2)$ & $56(47.5)$ & $60(56.8)$ & \\
\hline Recurrent & $304(44.3)$ & $79(47.6)$ & $225(43.2)$ & & $120(50.8)$ & $62(52.5)$ & $58(49.2)$ & \\
\hline Tumor differentiation & & & & 0.111 & & & & 0.933 \\
\hline Well, moderate & $167(24.3)$ & $50(30.1)$ & $117(22.5)$ & & $67(28.4)$ & $34(28.8)$ & $33(28.0)$ & \\
\hline Poor & $186(27.1)$ & $43(25.9)$ & $143(27.4)$ & & $61(25.8)$ & $30(25.4)$ & $31(26.3)$ & \\
\hline Signet ring cell & $171(24.9)$ & $32(19.3)$ & $139(26.7)$ & & $59(25.0)$ & $28(23.7)$ & $31(26.3)$ & \\
\hline Combined, others & $163(23.7)$ & $41(24.7)$ & $122(23.4)$ & & $49(20.8)$ & $26(22.0)$ & $23(19.5)$ & \\
\hline Peritoneal metastasis & & & & 0.003 & & & & 0.686 \\
\hline No & $373(54.3)$ & $107(64.5)$ & $266(51.1)$ & & $148(62.7)$ & $72(61.0)$ & $76(64.4)$ & \\
\hline Yes & $314(45.7)$ & 59 (35.5) & $255(48.9)$ & & $88(37.3)$ & $46(39.0)$ & $42(35.6)$ & \\
\hline Liver metastasis & & & & 0.915 & & & & 0.382 \\
\hline No & $535(77.9)$ & $130(78.3)$ & $405(77.7)$ & & $171(72.5)$ & $89(75.4)$ & $82(69.5)$ & \\
\hline Yes & $152(22.1)$ & $36(21.7)$ & $116(22.3)$ & & $65(27.5)$ & $29(24.6)$ & $36(30.5)$ & \\
\hline Palliative surgical resection & & & & 0.182 & & & & 0.731 \\
\hline No & $549(79.9)$ & $139(83.7)$ & $410(78.7)$ & & $195(82.6)$ & $96(81.4)$ & $99(83.9)$ & \\
\hline Yes & $138(20.1)$ & $27(16.3)$ & $111(21.3)$ & & $41(17.4)$ & $22(18.6)$ & $19(16.1)$ & \\
\hline
\end{tabular}

${ }^{a}$ PS 3: 2 patients

$N$ number, PS performance status, ECOG Eastern Cooperative Oncology Group

therapy was performed in 138 patients (primary metastatic: 96, recurrent: 42). Among them, 60 patients underwent complete resection of tumor lesion(s) without gross residual disease. The reasons for performing palliative surgical resection before chemotherapy were previous described [19]. All the patients with primary metastatic disease were in AJCC stage IV, except for two stage III patients with gross residual disease after resection. Seven patients with primary metastatic disease who had undergone complete resection of the primary tumor with regional lymph node dissection had positive tumor cells in peritoneal cytology only.

First-line chemotherapy was combination therapy for 521 patients $(75.8 \%)$ and single-agent therapy for 166 patients (24.2\%). CC included: 5-FU/leucovorin/oxaliplatin
(359 patients), S1/cisplatin (74), capecitabine/oxaliplatin (22), capecitabine or 5-FU/cisplatin/trastuzumab (9), and others (57). SC included S1 (146 patients) and others (20). $\mathrm{SC}$ was more frequently performed in older patients $(\geq 70$ years $)(p<0.0001)$ and in patients with poor PS $(p<$ $0.0001)$, while a higher proportion of patients with peritoneal metastasis received CC $(p=0.003)$ (Table 1). For PSM, clinicopathological characteristics at the start of first-line chemotherapy were used as covariates, which were well balanced after 1:1 PSM (Table 1).

\section{Clinicopathological characteristics according to NLR and PLR}

Table 2 summarizes the patients' clinicopathological characteristics according to NLR and PLR. The median 
Table 2 Patients characteristics according to neutrophil-to-lymphocyte ratio /platelet-to-lymphocyte ratio

\begin{tabular}{|c|c|c|c|c|c|c|c|}
\hline \multirow[t]{2}{*}{ Characteristics } & \multirow{2}{*}{$\begin{array}{l}\text { Total N } \\
(\%)\end{array}$} & \multicolumn{2}{|l|}{ NLR } & \multirow[t]{2}{*}{$P$ value } & \multicolumn{2}{|l|}{ PLR } & \multirow[t]{2}{*}{$P$ value } \\
\hline & & Low & $\mathrm{High}^{a}$ & & Low & $\mathrm{High}^{\mathrm{b}}$ & \\
\hline Gender & & & & 0.116 & & & 0.562 \\
\hline Male & $478(69.6)$ & $229(66.8)$ & $249(72.4)$ & & $243(70.6)$ & $235(68.5)$ & \\
\hline Female & $209(30.4)$ & $114(33.2)$ & $95(27.6)$ & & $101(29.4)$ & $108(31.5)$ & \\
\hline Age (years) & & & & 0.375 & & & 0.235 \\
\hline$<70$ & $562(81.8)$ & $276(80.5)$ & $286(83.1)$ & & $275(79.9)$ & $287(83.7)$ & \\
\hline$\geq 70$ & $125(18.2)$ & $67(19.5)$ & $58(16.9)$ & & $69(20.1)$ & $56(16.3)$ & \\
\hline PS (ECOG) & & & & 0.020 & & & 0.333 \\
\hline 0,1 & $611(88.9)$ & $315(91.8)$ & $296(86.0)$ & & $310(90.1)$ & $301(87.8)$ & \\
\hline 2,3 & $76(11.1)^{c}$ & $28(8.2)$ & $48(14.0)$ & & $34(9.9)$ & $42(12.2)$ & \\
\hline Disease status & & & & $<0.0001$ & & & $<0.0001$ \\
\hline Primary metastatic & $383(55.7)$ & $155(45.2)$ & $228(66.3)$ & & $166(48.3)$ & $217(63.3)$ & \\
\hline Recurrent & $304(44.3)$ & $188(54.8)$ & $116(33.7)$ & & $178(51.7)$ & $126(36.7)$ & \\
\hline Tumor differentiation & & & & 0.166 & & & 0.777 \\
\hline Well, moderate & $167(24.3)$ & $92(26.8)$ & $75(21.8)$ & & $88(25.6)$ & $79(23.0)$ & \\
\hline Poor & $186(27.1)$ & $83(24.2)$ & $103(29.9)$ & & $95(27.6)$ & $91(26.5)$ & \\
\hline Signet ring cell & $171(24.9)$ & 81 (23.6) & $90(26.2)$ & & $81(23.5)$ & $90(26.2)$ & \\
\hline Combined, others & $163(23.7)$ & $87(25.4)$ & $76(22.1)$ & & $80(23.3)$ & $83(24.2)$ & \\
\hline Peritoneal metastasis & & & & 0.039 & & & $<0.0001$ \\
\hline No & $373(54.3)$ & $200(58.3)$ & $173(50.3)$ & & $220(64.0)$ & $153(44.6)$ & \\
\hline Yes & $314(45.7)$ & $143(41.7)$ & $171(49.7)$ & & $124(36.0)$ & $190(55.4)$ & \\
\hline Liver metastasis & & & & 1.000 & & & 0.004 \\
\hline No & $535(77.9)$ & $267(77.8)$ & $268(77.9)$ & & $252(73.3)$ & $283(82.5)$ & \\
\hline Yes & $152(22.1)$ & $76(22.2)$ & $76(22.1)$ & & $92(26.7)$ & $60(17.5)$ & \\
\hline 1st line $C T x$ & & & & 0.286 & & & 0.929 \\
\hline Single-agent & $166(24.2)$ & $89(25.9)$ & $77(22.4)$ & & $84(24.4)$ & $82(23.9)$ & \\
\hline Combination & $521(75.8)$ & $254(74.1)$ & $267(77.6)$ & & $260(75.6)$ & $261(76.1)$ & \\
\hline Palliative surgical resection & & & & $<0.0001$ & & & 0.775 \\
\hline No & $549(79.9)$ & $250(72.9)$ & $299(86.9)$ & & $273(79.4)$ & $276(80.5)$ & \\
\hline Yes & $138(20.1)$ & $93(27.1)$ & $45(13.1)$ & & $71(20.6)$ & $67(19.5)$ & \\
\hline PLR & & & & $<0.0001$ & & & - \\
\hline Low & $344(50.1)$ & $248(72.3)$ & $96(27.9)$ & & - & - & \\
\hline High & $343(49.9)$ & $95(27.7)$ & $248(72.1)$ & & - & - & \\
\hline
\end{tabular}

${ }^{\mathrm{a}}>$ median (2.67), ${ }^{\mathrm{b}}>$ median (167.21). ${ }^{\mathrm{c}}$ PS 3: 2 patients

NLR neutrophil-to-lymphocyte ratio, PLR platelet-to-lymphocyte ratio, $\boldsymbol{N}$ number, PS performance status, ECOG Eastern Cooperative Oncology Group, CTx Chemotherapy

NLR and PLR were $2.67(0.54-24.5)$ and $167.21(10.53-$ 851.44), respectively. High NLR and PLR were both associated with a high proportion of primary metastatic disease $(p<0.0001$, in each case) and peritoneal metastasis $(p=0.039$ and $p<0.0001$, respectively). While high NLR was associated with a high proportion of poor PS $(p=0.02)$ and no palliative resection $(p<0.0001)$, high PLR was associated with a high proportion of absence of liver metastasis $(p=0.004)$. NLR and PLR correlated with each other significantly $(p<0.0001)$.

\section{Overall survival}

The median follow-up duration for the survivors was 85 months (43-171 months). Only one patient was lost to follow-up at 1 month after the initiation of first-line chemotherapy, while included in survival analysis as censored data. At the time of the last follow-up, 35 patients (5.1\%) were still alive. The median OS of all patients after initiation of first-line therapy was 10 months. The median OS of patients who received first-line $\mathrm{CC}$ was 
significantly longer than that of the patients who received SC (11 vs. 8 months, $p<0.0001$ ) (Fig. 1a).

In univariate analysis, patients who underwent surgical resection before first-line chemotherapy $(p<0.0001)$ and second- or further-line therapy $(p<0.0001)$ demonstrated longer median OS, as in first-line CC. Old age (70 years or older) $(p=0.012)$, poor PS $(p<0.0001)$, signet ring cell histology $(p=0.022)$, presence of peritoneal metastasis $(p=0.001)$, high NLR $(p<0.0001)$, and high PLR $(p<$ 0.0001 ) were associated with poor OS (Table 3, Figs. 1b, c). Although patients with CC showed better OS in the majority of subgroups, no difference in OS between CC and SC were observed in patients with old age $(p=0.583$, Fig. 2b), ECOG PS 2 or $3(p=0.810)$, signet ring cell and combined/other histology $(p=0.347$ and $p=0.451$, respectively), palliative surgical resection $(p=0.307)$, and high PLR ( $p=0.120)$ (Fig. 3). There was a significant interaction between age and type of regimen (CC vs. SC) ( $p=$ 0.012) (Fig. 3).

Multivariate analysis revealed that palliative resection and $\geq$ second-line chemotherapy were independently associated with favorable OS $(p<0.0001$, in each case), whereas ECOG PS 2 or $3(p=0.004)$, poorly differentiated and signet ring cell histology $(p=0.015$ and $p<$ 0.0001 , respectively), peritoneal metastasis $(p=0.04)$, high NLR $(p=0.001)$, and high PLR $(p=0.033)$ were independent prognostic factors of poor OS (Table 3). CC was not independently associated with favorable OS (Table 3). Given the strong correlation between NLR and PLR, we performed multivariate analysis that included only one of the two on each occasion. Both high NLR and high PLR were independent prognostic factor of poor OS in these analyses $(p<0.0001$, in each case, detailed data not shown).

After PSM, there was no significant difference in OS between CC and SC ( $p=0.322)$, while poor PS, palliative resection, and $\geq$ second-line chemotherapy still demonstrated independent prognostic significance (Fig. 2c and Table 3). In addition, no significant difference in OS between $\mathrm{CC}$ and $\mathrm{SC}$ was also observed in old age $(p=$ $0.348)$ and ECOG 2 or $3(p=0.461)$ patients in the PSM cohort.

\section{Discussion}

In the present study, patients with old age or poor PS patients underwent SC more frequently despite the significantly higher proportion of RPMGC patients with CC. On the other hand, $\mathrm{CC}$ was more commonly used in patients with peritoneal metastases. The most likely explanation for these findings is that oncologists judged that $\mathrm{CC}$ was too toxic for elderly patients and those with poor PS, whereas patients with peritoneal metastases required aggressive treatment, given its association with poor outcome. Although CC demonstrated an OS benefit in univariate analysis, it was not associated with favorable outcome in several subgroups such as elderly patients, and had no prognostic significance in multivariate analysis.

Large phase III trials to compare CC and SC incorporating third generation agents, such as $\mathrm{S}-1$, docetaxel and irinotecan, have been conducted in Japan and have shown conflicting results $[4,8-10]$. In two trials, adding cisplatin or docetaxel to S-1 showed an OS benefit over S-1 alone $[9,10]$. However, no significant difference in OS was observed between CC and S-1 monotherapy in two other trials $[4,8]$. A recent meta-analysis of chemotherapy in advanced gastric cancer indicated that survival was significantly but slightly improved (about 1 month) with CC compared to SC [7]. Only a few retrospective studies have compared the outcomes between $\mathrm{CC}$ and SC. Two large retrospective studies demonstrated that CC was superior to SC in terms of OS [20,

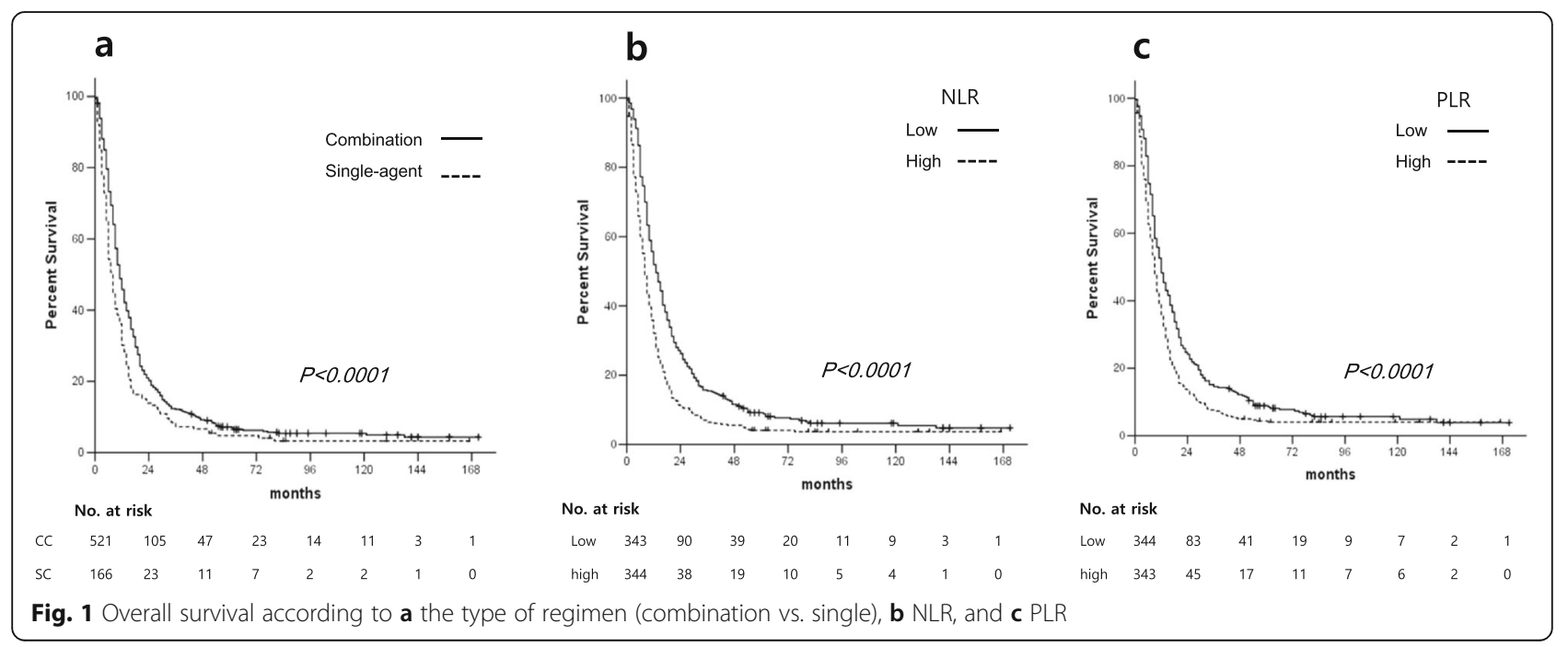


Table 3 Univariate and multivariate analysis of overall survival from the start of first-line chemotherapy

\begin{tabular}{|c|c|c|c|c|c|c|c|c|c|c|}
\hline \multirow[t]{3}{*}{ Prognostic Factors } & \multicolumn{5}{|c|}{ Before propensity score matching } & \multicolumn{5}{|c|}{ After propensity score matching } \\
\hline & \multicolumn{2}{|l|}{ Univariate } & \multicolumn{3}{|c|}{ Multivariate } & \multicolumn{2}{|l|}{ Univariate } & \multicolumn{3}{|c|}{ Multivariate } \\
\hline & $\begin{array}{l}\text { MS } \\
\text { (months) }\end{array}$ & $P$ value $^{\mathrm{a}}$ & $\mathrm{HR}$ & $95 \% \mathrm{Cl}$ & $P$ value $^{\mathrm{b}}$ & MS (months) & $P$ value $^{\mathrm{a}}$ & $\overline{H R}$ & $95 \% \mathrm{Cl}$ & $P$ value \\
\hline Gender & & 0.728 & & & & & 0.688 & & & \\
\hline Male & 10 & & & & & 9 & & & & \\
\hline Female & 10 & & & & & 8 & & & & \\
\hline Age (years) & & 0.012 & & & & & 0.565 & & & \\
\hline$<70$ & 11 & & 1 & & & 9 & & & & \\
\hline$\geq 70$ & 8 & & 1.01 & $0.80-1.27$ & 0.941 & 9 & & & & \\
\hline PS (ECOG) & & $<0.0001$ & & & & & $<0.0001$ & & & \\
\hline 0,1 & 11 & & 1 & 1 & & 10 & & 1 & 1 & \\
\hline$\geq 2$ & 5 & & 1.47 & $1.13-1.92$ & 0.004 & 5 & & 1.59 & $1.10-2.28$ & 0.013 \\
\hline Disease status & & 0.315 & & & & & 0.336 & & & \\
\hline Primary metastatic & 10 & & & & & 8 & & & & \\
\hline Recurrent & 10 & & & & & 10 & & & & \\
\hline Tumor differentiation & & 0.022 & & & & & 0.215 & & & \\
\hline Well, moderate & 12 & & 1 & & & 11 & & & & \\
\hline Poor & 10 & & 1.32 & $1.06-1.65$ & 0.015 & 9 & & & & \\
\hline Signet ring cell & 8 & & 1.64 & $1.30-2.07$ & $<0.0001$ & 7 & & & & \\
\hline Combined, others & 11 & & 1.21 & $0.96-1.53$ & 0.102 & 12 & & & & \\
\hline Peritoneal metastasis & & 0.001 & & & & & 0.037 & & & \\
\hline No & 11 & & 1 & & & 10 & & 1 & & \\
\hline Yes & 9 & & 1.19 & $1.01-1.40$ & 0.040 & 7 & & 1.25 & $0.96-1.64$ & 0.099 \\
\hline Liver metastasis & & 0.595 & & & & & 0.613 & & & \\
\hline No & 11 & & & & & 9 & & & & \\
\hline Yes & 9 & & & & & 9 & & & & \\
\hline Palliative resection & & $<0.0001$ & & & & & $<0.0001$ & & & \\
\hline No & 9 & & 1 & & & 8 & & 1 & & \\
\hline Yes & 19 & & 0.42 & $0.34-0.52$ & $<0.0001$ & 15 & & 0.59 & $0.41-0.85$ & 0.005 \\
\hline 1st line $C T x$ & & $<0.0001$ & & & & & 0.322 & & & \\
\hline Single-agent & 8 & & 1 & & & 8 & & & & \\
\hline Combination & 11 & & 0.82 & $0.66-1.02$ & 0.069 & 10 & & & & \\
\hline CTx lines & & $<0.0001$ & & & & & $<0.0001$ & & & \\
\hline 1st line $C T x$ & 6 & & 1 & & & 6 & & 1 & & \\
\hline$\geq$ 2nd line $C T x$ & 14 & & 0.69 & $0.59-0.82$ & $<0.0001$ & 13 & & 0.59 & $0.45-0.77$ & $<0.0001$ \\
\hline NLR & & $<0.0001$ & & & & & 0.013 & & & \\
\hline Low & 13 & & 1 & & & 10 & & 1 & & \\
\hline High & 8 & & 1.35 & $1.14-1.61$ & 0.001 & 7 & & 1.25 & $0.95-1.65$ & 0.111 \\
\hline PLR & & $<0.0001$ & & & & & 0.539 & & & \\
\hline Low & 12 & & 1 & & & 9 & & & & \\
\hline High & 9 & & 1.21 & $1.02-1.44$ & 0.033 & 8 & & & & \\
\hline
\end{tabular}

${ }^{\mathrm{a}}$ Log-rank test, ${ }^{\mathrm{b}} \mathrm{Cox}$ proportional-hazards regression model

MS median survival, HR hazard ratio, PS performance status, ECOG Eastern Cooperative Oncology Group, CTx chemotherapy, NLR neutrophil-to-lymphocyte ratio,

$P L R$ platelet-to-lymphocyte ratio 


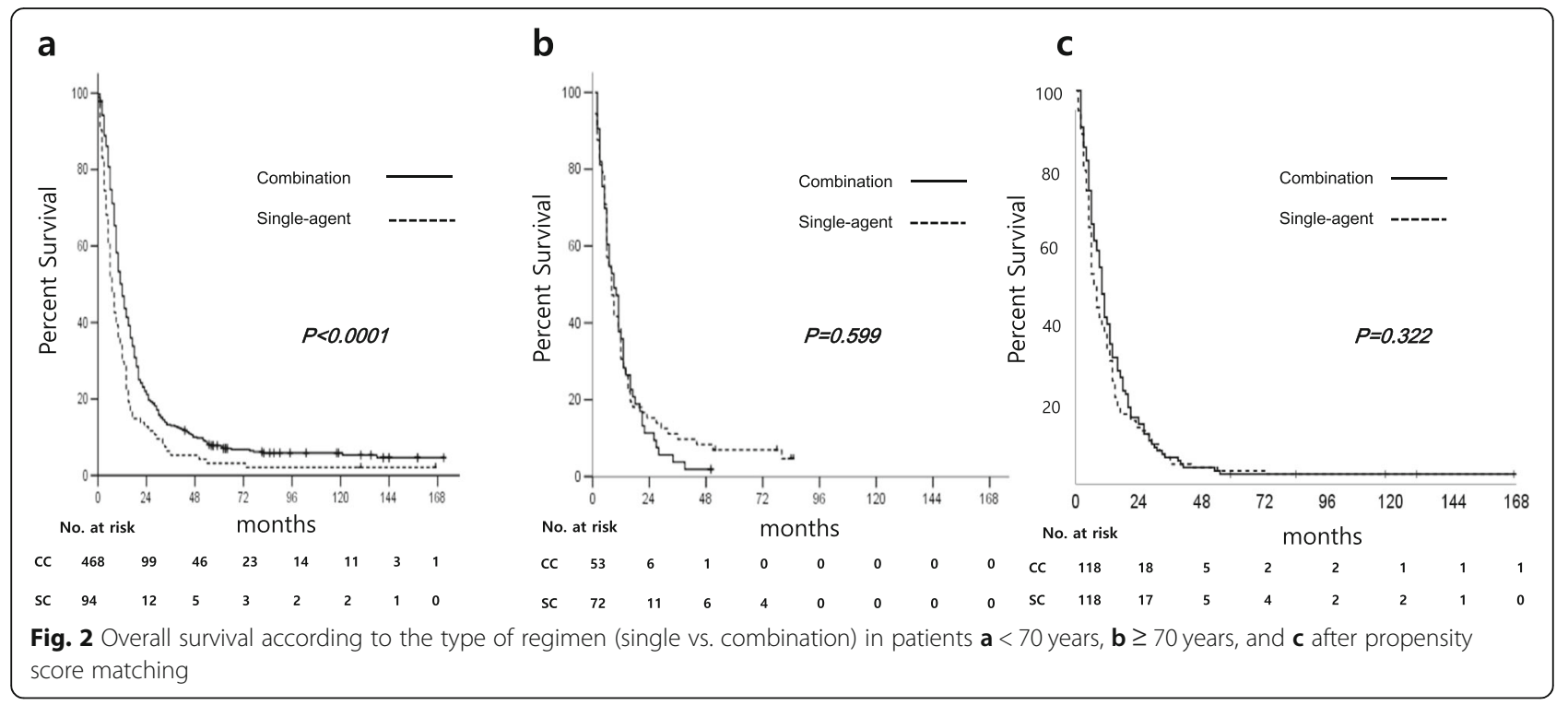

21]. However, unlike the present study, neither retrospective study investigated the relationship between chemotherapy regimen and important clinical characteristics such as age, PS, and palliative resection [20, 21]. Moreover, because most randomized trials have included relatively young patients and patients with good PS, it is difficult to define the best chemotherapy strategy for elderly patients or those with poor PS [3-5, 8-11].

In the present study, no difference in OS between CC and SC was observed in patients with old age, ECOG PS

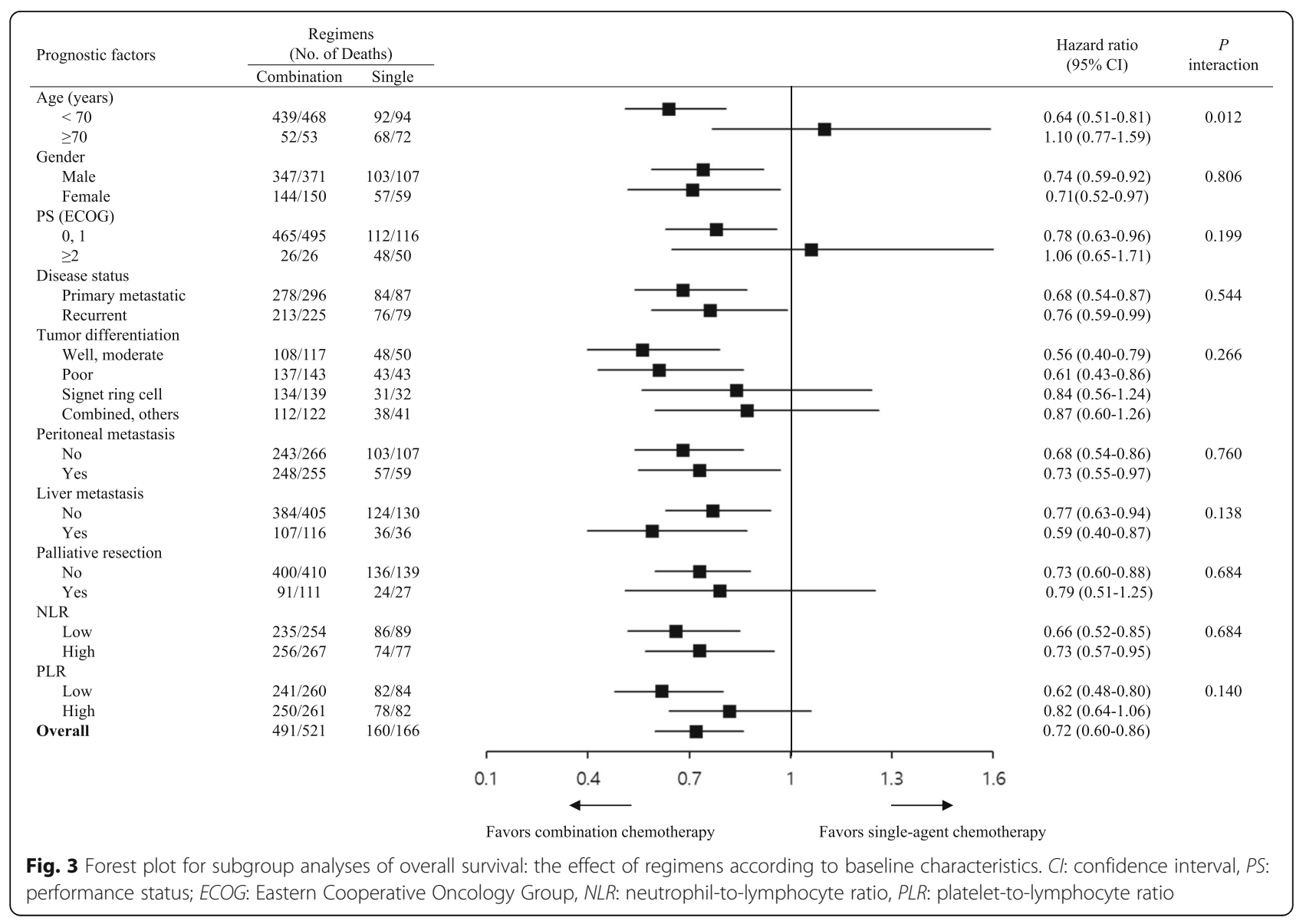


2 or 3, signet ring cell and combined/other histology, palliative surgical resection, and high PLR. Despite a lack of significant interaction between ECOG PS and type of regimen probably due to the small number of patients with PS 2 or 3, SC showed similar OS compared to CC. Given the relatively high risk of chemotherapy-related toxicities in CC, SC could be recommended in clinical practice for patients with poor PS. In patients with palliative surgical resection before first-line chemotherapy, there was no significant difference in OS between the $\mathrm{CC}$ and SC groups. Low tumor burden after palliative resection may be related to this result. However, routine use of SC in patients with palliative resection before chemotherapy cannot be recommended on the basis of these findings, given the retrospective nature of the present study, without significant interaction between surgical resection and chemotherapy regimen.

Limited data are available regarding chemotherapy regimens for elderly patients with RPMGC, because such patients are underrepresented in clinical trials [3-5, 811]. Two small retrospective studies comparing S-1 with S-1 and cisplatin (SP) for RPMGC patients older than 70 gave conflicting results, with both studies showing more severe toxicities in the SP group [11, 22]. Two larger retrospective studies from Korea and Japan for elderly patients demonstrated no difference in OS between CC and SC $[3,5]$. In one of these studies, there was no significant difference in OS between the S-1 and SP groups, even after propensity score matching [3]. Furthermore, in a small phase III trial from Korea, comparing capecitabine with capecitabine and oxaliplatin in 50 elderly ( $\geq 70$ years) RPMGC patients, there was no significant difference in OS, with higher incidence of some toxicities in CC arm [23]. In the current study cohort of elderly patients ( $\geq 70$ years), only $3.8 \%$ of the CC group were in PS 2, while $25 \%$ of the SC group were in PS 2 $(p=0.001)$. Despite a significantly higher proportion of patients with good PS in the CC group, there was no difference in OS between the two groups in elderly patients. This finding and the significant interaction between regimen (CC vs. SC) and age suggest that $\mathrm{CC}$ may not be beneficial compared to SC in elderly patients with RPMGC, especially those aged 70 years or more. Given the results of the present study and previous investigations, SC can be recommended as a reasonable option for elderly patients, especially those with poor PS or comorbidity, although randomized trials are essential to define the standard chemotherapy regimen.

Considering imbalance in age and PS, well-established prognostic factors, between $\mathrm{CC}$ and $\mathrm{SC}$ groups, in the present cohort, PSM analysis was performed by adjusting patient characteristics before the initiation of chemotherapy as covariates. After PSM, there was no difference in OS between CC and SC groups. Increased proportion of patients with old age and ECOG PS 2 or 3 (10.2 to $31.4 \%$ and 5.0 to $18.6 \%$, respectively) in CC group after PSM may be attributable to this result. In addition, no difference in OS between CC and SC was observed in old age and poor PS patients after PSM. These findings also suggest that SC could be useful option with less toxicity in elderly and poor PS patients.

Inflammation plays a critical role in the development and progression of various cancers [12-14]. Of the various inflammatory markers, NLR and PLR have been suggested as potential prognostic markers in various cancers [12-16]. A high NLR reflects a decrease in the number of lymphocytes and/or an elevated number of neutrophils. Neutrophils may play an important role in the development and progression of cancer by offering a suitable microenvironment for their growth [14, 24, 25]. Circulating neutrophils may secrete vascular endothelial growth factor (VEGF), interleukin-18, and matrix metalloproteinase, which are closely associated with tumorigenesis, progression and metastasis [14, 15, 24, 25]. Furthermore, the antitumor immune responses of activated $\mathrm{T}$ cells and natural killer cells may be inhibited by an elevated number of neutrophils surrounding tumor tissues [14, 24, 25]. Therefore, an elevated neutrophil count may have a negative effect on cancer patients, leading to poor outcome. In addition, because lymphocyte plays a crucial role in cellular adaptive immunity against cancer by attacking tumor cells at the outset of tumorigenesis, lymphopenia may reflect suppressed cell-mediated immunity against cancer [13-16].

An elevated level of PLR also represents an increased number of platelets and/or a decreased number of lymphocytes. Elevated platelet counts may promote the metastatic potential of tumor cells in various biological pathways [13, 16, 24]. Platelets may secrete cellular growth factors such as platelet-derived growth factor, VEGF, transforming growth factor beta, and platelet factor 4, thereby stimulating tumor angiogenesis and growth [13, 16, 24]. In addition, platelets can activate the invasiveness of tumor cells by enhancing the formation of tumor stroma and supporting the adhesion of tumor cells to the endothelium $[13,16]$. Furthermore, in the bloodstream, interactions between tumor cells and platelets could facilitate tumor cell metastasis by impeding the clearance of tumor cells by immune cells $[13,16]$.

In RPMGC, several studies have reported a significant association between high NLR or PLR and poor OS in patients treated with palliative chemotherapy $[12,14,15$, 24-26]. In the present study, both NLR and PLR were independently associated with poor OS in RPMGC patients who received palliative chemotherapy. NLR correlated significantly with PS and palliative resection, well-established prognostic factors in RPMGC, but there 
was no significant association between PLR and the same factors.

One interesting finding in the current study is that there was no significant difference in OS between CC and SC in the high PLR group, despite the lack of interaction between PLR and regimen. A possible explanation for similar OS between CC and SC in the high PLR group is that high platelet counts reflect aggressive behavior of tumors that are refractory even to CC. Alternatively, CC may decrease lymphocyte count more than SC, leading to greatly suppressed cell-mediated immunity against cancer cells. Chemotherapy-induced lymphopenia is commonly observed event, especially in dose-dense regimens [27, 28]. Moreover, a few studies showed significant association between lymphopenia after chemotherapy with or without radiotherapy and poor outcome in several solid tumors $[27,29]$.

Having analyzed a relatively large number of patients, the present study reported comparable OS between CC and SC in certain subgroups of RPMGC patients, which might provide useful information for clinical decisionmaking. However, the current study has several limitations. First, it is a retrospective analysis from a single institution. Second, a variety of chemotherapy regimens were used in several therapy lines. Third, because the data were not prospectively collected, we did not analyze chemotherapy-related toxicities. Fourth, a very small number of patients were treated with first-line trastuzumab containing regimen, owing to the approval time of trastuzumab in Korea. Finally, because the optimal cutoff values of NLR and PLR have not yet been determined, application of the data from the present study to clinical practice requires further validation $[14,16]$. Nonetheless, because the present study analyzed all patients who underwent palliative chemotherapy during the defined period with mature follow-up (minimum follow-up duration of survivors: 43 months), the results may reflect treatment outcomes in real-world clinical practice.

\section{Conclusion}

Although CC is the standard of care in RPMGC, SC can be considered a reasonable option in certain subgroups, such as elderly patients.

\footnotetext{
Abbreviations

CBC: Complete blood count; CC: Combination chemotherapy; ECOG: Eastern Cooperative Oncology Group; GC: Gastric cancer; IRB: Institutional Review Board; NLR: Neutrophil-to-lymphocyte ratio; OS: Overall survival; PLR: Plateletto-lymphocyte ratio; PS: Performance status; PSM: Propensity score matching; RPMGC: Recurrent or primary metastatic gastric cancer; SC: Single-agent chemotherapy; SP: S-1 and cisplatin; VEGF: Vascular endothelial growth factor
}

\section{Acknowledgments}

This study was presented in part as a poster at ESMO 2018 Congress, Munich, Germany, 2018.
Authors' contributions

JHC, YWC, SYK, GSJ, HWL, SHJ, JSP and MSA collected and analyzed clinical data. JHC, YWC, SYK and MSA wrote the main manuscript. JHC, MSA and SSS performed statistical analysis. All authors read and approved the final manuscript.

\section{Funding}

This study was supported in part by National Research Foundation of Korea to Yong Won Choi at Ajou University (NRF-2018M3A9E8023857). The funder did not have any role in the design and conduct of study, the analysis and interpretation of the date, decision to publish and preparation of the manuscript.

\section{Availability of data and materials}

It is regrettable that we will not be able to provide the raw data of the present study. Under the current South Korean law (Bioethics and Safety Act), data of human subjects including personal information, even in deidentified form, can be provided to a third party only after obtaining a written consent from the subject. Because the present study is retrospective one about palliative chemotherapy for advanced cancer, it is practically impossible to get written consents from the patients at this point.

\section{Ethics approval and consent to participate}

The protocol was reviewed and approved by the Institutional Review Board (IRB) of Ajou University Hospital (IRB approval no. AJIRB-MED-MDB-18-317). The IRB decided to waive the informed consent for this study because it was a retrospective study using anonymized data.

\section{Consent for publication}

Not applicable.

\section{Competing interests}

The authors declare that they have no competing interests.

\section{Author details}

'Department of Hematology-Oncology, Ajou University School of Medicine, 164 World Cup-ro, Suwon, Yeongtong-gu 16499, South Korea. ${ }^{2}$ Department of Pulmonary and Critical Care Medicine, Ajou University School of Medicine, Suwon, South Korea.

Received: 24 July 2019 Accepted: 21 February 2020

Published online: 02 March 2020

\section{References}

1. Fitzmaurice C, Akinyemiju TF, Al Lami FH, Alam T, Alizadeh-Navaei R, Allen C, Alsharif U, Alvis-Guzman N, Amini E, Anderson BO, et al. Global, regional, and National Cancer Incidence, mortality, years of life lost, years lived with disability, and disability-adjusted life-years for 29 Cancer groups, 1990 to 2016: a systematic analysis for the global burden of disease study. JAMA Oncol. 2018;4(11):1553-68.

2. Jung KW, Won YJ, Kong HJ, Lee ES. Cancer statistics in Korea: incidence, mortality, survival, and prevalence in 2016. Cancer Res Treat. 2019;51(2):417-30.

3. Makiyama A, Kunieda K, Noguchi M, Kajiwara T, Tamura T, Takeda K, Sugiyama J, Minashi K, Moriwaki T, Sugimoto N, et al. First-line chemotherapy with S-1 alone or S-1 plus cisplatin for elderly patients with advanced gastric cancer: a multicenter propensity score matched study. Gastric Cancer. 2018:21(5):792-801.

4. Narahara $H$, lishi $H$, Imamura $H$, Tsuburaya A, Chin $K$, Imamoto H, Esaki T, Furukawa H, Hamada C, Sakata Y. Randomized phase III study comparing the efficacy and safety of irinotecan plus S-1 with S-1 alone as first-line treatment for advanced gastric cancer (study GC0301/TOP-002). Gastric Cancer. 2011;14(1):72-80

5. Sun DS, Jeon EK, Won HS, Park JC, Shim BY, Park SY, Hong YS, Kim HK, Ko $\mathrm{YH}$. Outcomes in elderly patients treated with a single-agent or combination regimen as first-line chemotherapy for recurrent or metastatic gastric cancer. Gastric Cancer. 2015:18(3):644-52

6. Wagner AD, Grothe W, Haerting J, Kleber G, Grothey A, Fleig WE. Chemotherapy in advanced gastric cancer: a systematic review and metaanalysis based on aggregate data. J Clin Oncol. 2006;24(18):2903-9. 
7. Wagner AD, Syn NL, Moehler M, Grothe W, Yong WP, Tai BC, Ho J, Unverzagt S. Chemotherapy for advanced gastric cancer. Cochrane Database Syst Rev. 2017. https://doi.org/10.1002/14651858.CD004064.

8. Boku N, Yamamoto S, Fukuda H, Shirao K, Doi T, Sawaki A, Koizumi W, Saito $H$, Yamaguchi K, Takiuchi $H$, et al. Fluorouracil versus combination of irinotecan plus cisplatin versus S-1 in metastatic gastric cancer: a randomised phase 3 study. Lancet Oncol. 2009;10(11):1063-9.

9. Koizumi W, Kim YH, Fujii M, Kim HK, Imamura H, Lee KH, Hara T, Chung HC, Satoh T, Cho JY, et al. Addition of docetaxel to S-1 without platinum prolongs survival of patients with advanced gastric cancer: a randomized study (START). J Cancer Res Clin Oncol. 2014;140(2):319-28.

10. Koizumi W, Narahara H, Hara T, Takagane A, Akiya T, Takagi M, Miyashita K, Nishizaki T, Kobayashi O, Takiyama W, et al. S-1 plus cisplatin versus S-1 alone for first-line treatment of advanced gastric cancer (SPIRITS trial): a phase III trial. Lancet Oncol. 2008;9(3):215-21.

11. Tsushima T, Hironaka S, Boku N, Machida N, Yamazaki K, Yasui H, Fukutom A, Todaka A, Taniguchi H, Onozawa Y, et al. Comparison of safety and efficacy of S-1 monotherapy and S-1 plus cisplatin therapy in elderly patients with advanced gastric cancer. Int J Clin Oncol. 2013;18(1):10-6.

12. Jeong JH, Lim SM, Yun JY, Rhee GW, Lim JY, Cho JY, Kim YR. Comparison of two inflammation-based prognostic scores in patients with unresectable advanced gastric cancer. Oncology. 2012;83(5):292-9.

13. Huang XZ, Chen WJ, Zhang X, Wu CC, Zhang CY, Sun SS, Wu J. An elevated platelet-to-lymphocyte ratio predicts poor prognosis and Clinicopathological characteristics in patients with colorectal Cancer: a meta-analysis. Dis Markers. 2017. https://doi.org/10.1155/2017/1053125.

14. Sun J, Chen X, Gao P, Song Y, Huang X, Yang Y, Zhao J, Ma B, Gao X, Wang Z. Can the neutrophil to lymphocyte ratio be used to determine gastric Cancer treatment outcomes? A systematic review and meta-analysis. Dis Markers. 2016. https://doi.org/10.1155/2016/7862469.

15. Kim H, Ro SM, Yang JH, Jeong JW, Lee JE, Roh SY, Kim IH. The neutrophilto-lymphocyte ratio prechemotherapy and postchemotherapy as a prognostic marker in metastatic gastric cancer. Korean J Intern Med. 2018; 33(5):990-9.

16. Zhang M, Huang XZ, Song YX, Gao P, Sun JX, Wang ZN. High platelet-tolymphocyte ratio predicts poor prognosis and Clinicopathological characteristics in patients with breast Cancer: a meta-analysis. Biomed Res Int. 2017. https://doi.org/10.1155/2017/9503025.

17. Edge SB. American joint committee on Cancer.: AJCC cancer staging manual. 7th ed. New York: Springer; 2010.

18. Choi YW, Ahn MS, Jeong GS, Lee HW, Jeong SH, Kang SY, Park JS, Choi JH, Sheen SS. The role of third-line chemotherapy in recurrent or metastatic gastric cancer: a cohort study with propensity score matching analysis. Medicine. 2018;97(39):e12588

19. Choi YW, Ahn MS, Jeong GS, Lee HW, Jeong SH, Kang SY, Park JS, Choi JH, Son SY, Hur H, et al. The role of surgical resection before palliative chemotherapy in advanced gastric cancer. Sci Rep. 2019;9(1):4136

20. Sougioultzis S, Syrios J, Xynos ID, Bovaretos N, Kosmas C, Sarantonis J, Dokou A, Tzivras D, Zografos G, Felekouras E, et al. Palliative gastrectomy and other factors affecting overall survival in stage IV gastric adenocarcinoma patients receiving chemotherapy: a retrospective analysis. Eur J Surg Oncol. 2011;37(4):312-8.

21. Warschkow R, Baechtold M, Leung K, Schmied BM, Nussbaum DP, Gloor B, Blazer lii DG, Worni M. Selective survival advantage associated with primary tumor resection for metastatic gastric cancer in a Western population. Gastric Cancer. 2018;21(2):324-37.

22. Terazawa T, Iwasa S, Takashima A, Nishitani H, Honma Y, Kato K, Hamaguchi T, Yamada Y, Shimada Y. Impact of adding cisplatin to S-1 in elderly patients with advanced gastric cancer. J Cancer Res Clin Oncol. 2013; 139(12):2111-6.

23. Hwang IG, Ji JH, Kang JH, Lee HR, Lee HY, Chi KC, Park SW, Lee SJ, Kim ST, Lee J, et al. A multi-center, open-label, randomized phase III trial of first-line chemotherapy with capecitabine monotherapy versus capecitabine plus oxaliplatin in elderly patients with advanced gastric cancer. J Geriatr Oncol. 2017:8(3):170-5.

24. Lee S, Oh SY, Kim SH, Lee JH, Kim MC, Kim KH, Kim HJ. Prognostic significance of neutrophil lymphocyte ratio and platelet lymphocyte ratio in advanced gastric cancer patients treated with FOLFOX chemotherapy. BMC Cancer. 2013;13:350.
25. Yamanaka T, Matsumoto S, Teramukai S, Ishiwata R, Nagai Y, Fukushima M. The baseline ratio of neutrophils to lymphocytes is associated with patient prognosis in advanced gastric cancer. Oncology. 2007;73(3-4):215-20.

26. Wang F, Liu ZY, Xia YY, Zhou C, Shen XM, Li XL, Han SG, Zheng Y, Mao ZQ, Gong FR, et al. Changes in neutrophil/lymphocyte and platelet/lymphocyte ratios after chemotherapy correlate with chemotherapy response and prediction of prognosis in patients with unresectable gastric cancer. Oncol Lett. 2015;10(6):3411-8.

27. Hong Chu-Yuan PJ, Yi-Sheng W, He-Ping P, Hui Y, Chu-Xiong Z, Guo-Jian L, Guo-Qiang W. The impact of chemotherapy-associated neutrophil/ lymphocyte counts on prognosis of adjuvant chemotherapy in colorectal cancer. BMC Cancer. 2013;13:177.

28. Tolaney SM, Najita J, Winer EP, Burstein HJ. Lymphopenia associated with adjuvant anthracycline/ taxane regimens. Clin Breast Cancer. 2008;8(4):352-6.

29. Stuart A, Grossman SE, Campian J, Wild AT, Herman JM, Laheru D, Brock M, Balmanoukian A, Ye X. Survival in Patients With Severe Lymphopenia Following Treatment With Radiation and Chemotherapy for Newly Diagnosed Solid Tumors. J Natl Compr Cancer Netw. 2015;13(10):1225-31.

\section{Publisher's Note}

Springer Nature remains neutral with regard to jurisdictional claims in published maps and institutional affiliations.
Ready to submit your research? Choose BMC and benefit from:

- fast, convenient online submission

- thorough peer review by experienced researchers in your field

- rapid publication on acceptance

- support for research data, including large and complex data types

- gold Open Access which fosters wider collaboration and increased citations

- maximum visibility for your research: over $100 \mathrm{M}$ website views per year

At $\mathrm{BMC}$, research is always in progress.

Learn more biomedcentral.com/submissions 